
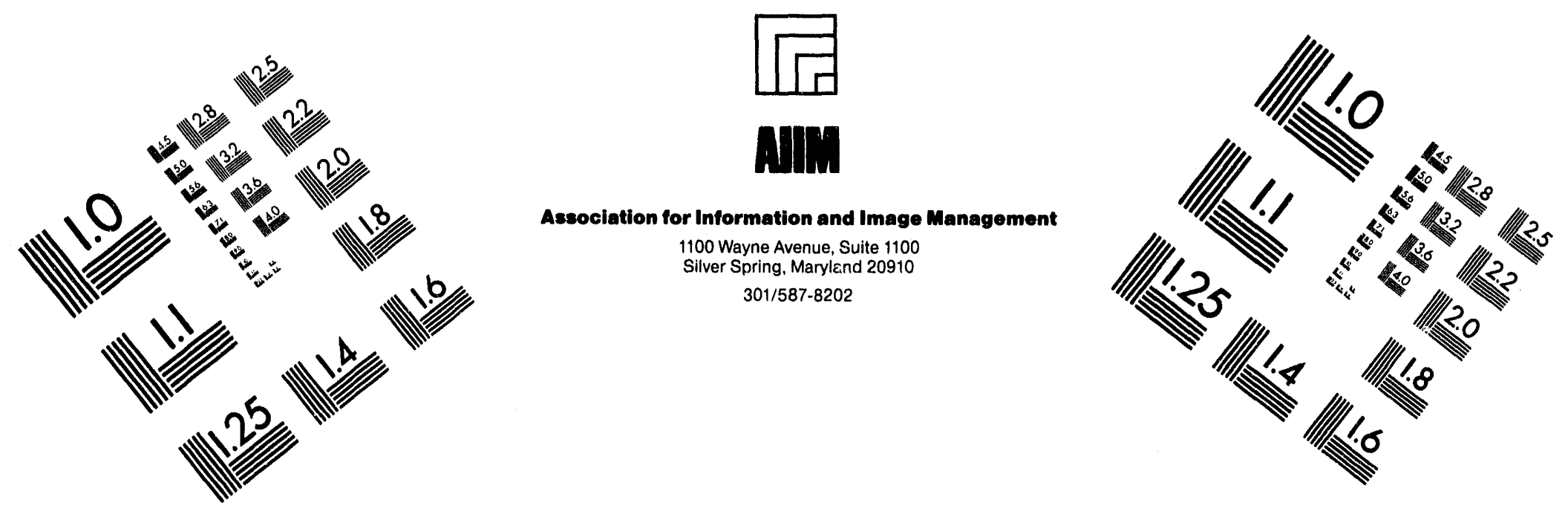

\title{
Centimeter
}

$\begin{array}{llllllllllllllll}1 & 2 & 3 & 4 & 5 & 6 & 7 & 8 & 9 & 10 & 11 & 12 & 13 & 14 & 15 & \mathrm{~mm}\end{array}$

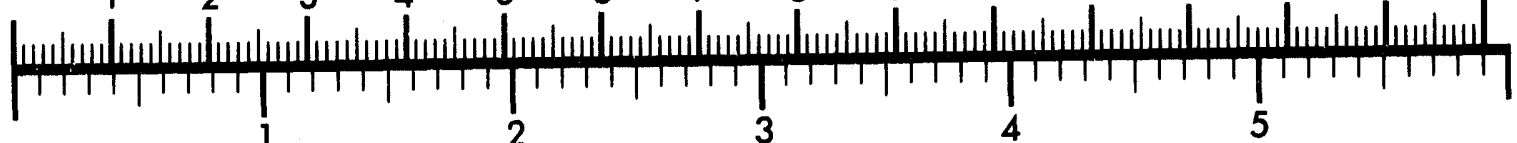
Inches

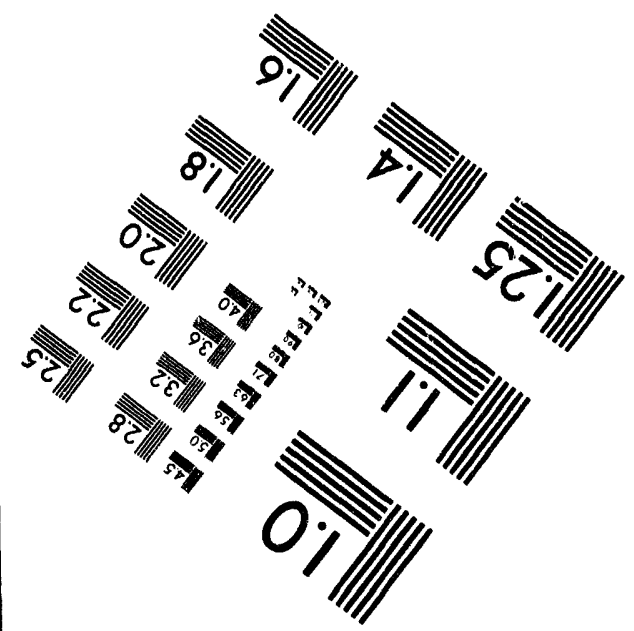

MANUFACTURED TO AIIM STANDARDS

BY APPLIED IMAGE, INC.

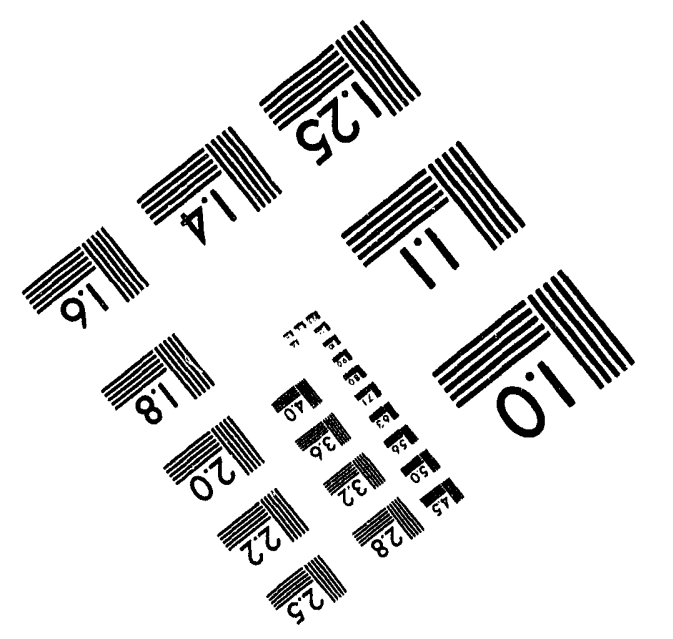



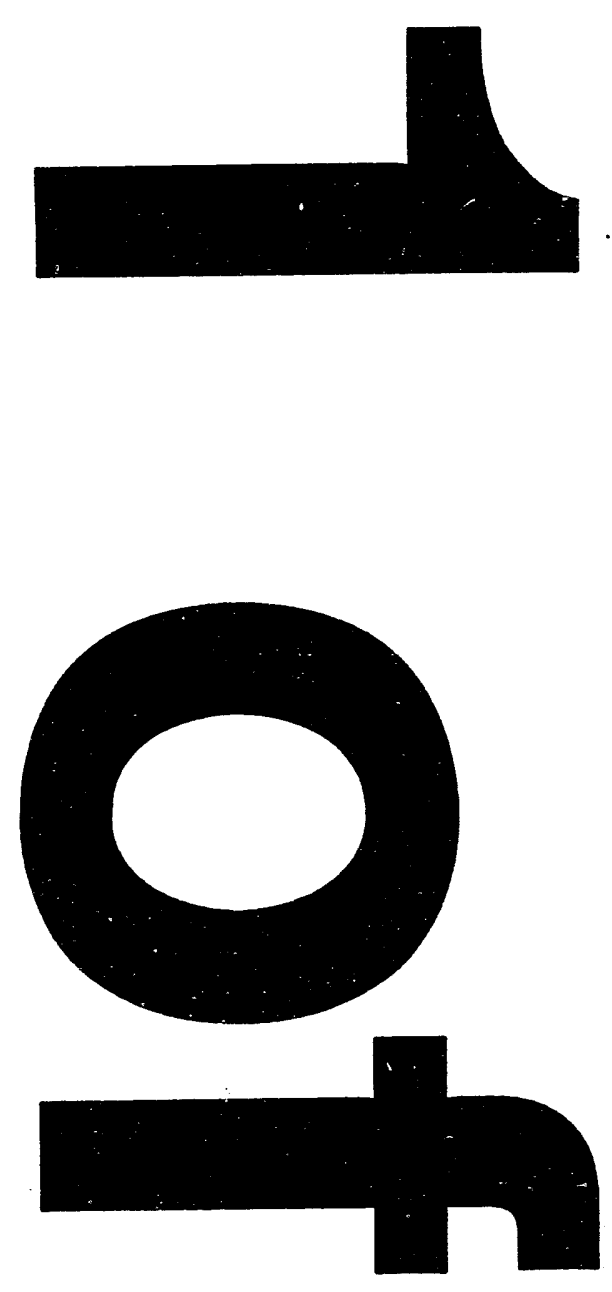

1

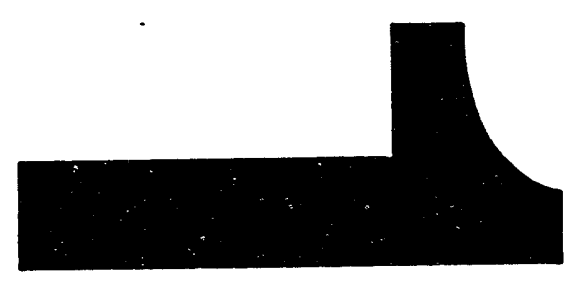




\title{
CONF-9408/3--4
}

\section{PREPARATION OF SILICA OR ALUMINA PILLARED CRYSTALLINE TITANATES ${ }^{*}$}

\author{
S. Udomsak , R. Nge ${ }^{a}$, D.C. Dufner ${ }^{b}$, S.E. Lott ${ }^{c}$, and R. G. Anthony"
}

a'Kinetics, Catalysis, and Reaction Engineering Laboratory, Department of Chemical Engineering, Texas A\&M University, College Station, TX 77843-3122, United States

'Electron Microscopy Center, Texas A\&M University, College Station, TX 77843-2257, United States

'Sandia National Laboratories, Albuquerque, NM 87185, United States

\begin{abstract}
Layered crystalline titanates (CT) [Anthony and Dosch, U.S. Patent 5177045 (1993)] are pillared with tetraethyl orthosilicate, 3-aminopropyltrimethoxysilane, and aluminum acetylacetonate to prepare porous and high surface area supports for sulfided NiMo catalyst. Tetra-ethyl orthosilicate or aluminum acetylacetonate intercalated CT are prepared by stepwise intercalation. First, the basal distance is increased by n-alkylammonium ions prior to intercalation with inorganic compounds. However, an aqueous solution of 3-aminopropyltrimethoxysilane could directly pillar CT without first swelling the titanate with $n$-alkylamine. The catalytic activities for hydrogenation of pyrene of sulfided NiMo supported silica or alumina pillared CT were higher than those of commercial catalysts (Shell324 and Amocat1C). The silicon and aluminum contents of the pillared CT, used as supports, have a considerable effect on the catalytic activities and physical properties of the supports.
\end{abstract}

\section{INTRODUCTION}

Anthony and Dosch $[1,2]$ prepared a series of new crystalline titanates (CT) by modifying the procedure used to prepare hydrous titanium oxide. CT with basal spacings of 1.0, 1.17, and $1.6 \mathrm{~nm}$ were prepared. The catalytic activities of Pd supported catalysts was varied depending on the type of CT. One labelled as type 2 titanate, when used as a precursor in the preparation of a supported Pd catalyst, had the highest activity for hydrogenation of pyrene and hexene among these Pd supported CT. However, CT was not thermally stable as reported by Anthony et al.[3]. For example, after calcination, the BET surface area of type 2 titanate decreased significantly, and crystalline $\mathrm{Na}_{0.23} \mathrm{TiO}_{2}$ phase formed.

\footnotetext{
- This work was performed at Texas A\&M University and Sandia National Laboratories. The work at Texas A\&M was funded by Sandia National Laboratories under Texas A\&M Research Foundation contract numbers 6806 and 8346. Sandia National Laboratories is supported by the US Department of Energy under contract number DE-AC04-94AL85000.
} 


\section{DISCLAIMER}

This report was prepared as an account of work sponsored by an agency of the United States Government. Neither the United States Government nor any agency thereof, nor any of their employees, makes any warranty, express or implied, or assumes any legal liability or responsibility for the accuracy, completeness, or usefulness of any information, apparatus, product, or process disclosed, or represents that its use would not infringe privately owned rights. Reference herein to any specific commercial product, process, or service by trade name, trademark, manufacturer, or otherwise does not necessarily constitute or imply its endorsement, recommendatior, or favoring by the United States Government or any agency thereof. The views and opinions of authors expressed herein do not necessarily state or reflect those of the United States Government or any agency thereof. 
There has been a great deal of interest to prepare layered compounds such as clays, silicates, double hydroxides, phosphates, oxides, and perovskite compounds with high thermal stability by using inorganic compounds to pillar the layered materials. These pillared materials have a high potential for use as catalyst supports. Recently, Clearfield and Kuchenmeister [4] and Clearfield et. al. [5] published reviews on pillared layered compounds. Aluminum Keggin ions $\left[\mathrm{Al}_{13} \mathrm{O}_{4}\left(\mathrm{OH}_{24}\right)\left(\mathrm{H}_{2} \mathrm{O}\right)_{12}\right]^{7+}$ and tetraethyl orthosilicate were usually used to prepare silica or alumina pillared materials by pillaring them into, $\mathbf{n}$-alkylammonium expanded materials. Cheng and Wang [6] used this technique to prepare alumina pillared tetratitanate, while silica pillared layered oxides were prepared by Landis et. al. $[7,8]$ using a similar technique. However, Li et.al. [9] also showed that siliconamine compounds could directly pillar layered material without first expanding the layers by n-alkylamine. Udomsak and Anthony [10] showed that tetraethyl orthosilicate can be used to pillar type 2 titanate by a procedure similar to Landis's.

In this manuscript, the preparation, characterization, and catalytic activity of silica or alumina pillared CT are shown. The catalytic activity of sulfided NiMo supported catalysts was evaluated by using the model reaction, hydrogenation of pyrene at $573 \mathrm{~K}$.

\section{EXPERIMENTAL}

\subsection{Catalyst Preparation}

Titanium(IV) isopropoxide, an aqueous solution of sodium hydroxide, a solution of tetramethylammonium hydroxide in methanol, aluminum nitrate nonahydrate and tetrapropylammonium bromide were used in the preparation of sodium CT. These chemicals were mixed to produce a white slurry. The slurry was loaded into a closed reactor and heated in an oven set at a temperature in the range of $423-473 \mathrm{~K}$. The crystallization time was varied between twelve hours to two days. The synthesis details were presented by Anthony and Dosch [2]. Sodium CT was acidified by ion exchanging with an aqueous solution of $\mathrm{HCl}$ at $\mathrm{pH}$ of 2.0 for several times to remove $\mathrm{Na}^{+}$.

In order to intercalate tetraethyl orthosilicate (TEOS) or aluminum acetylacetonate (AIAc) into CT, the acidified CT was first refluxed with an aqueous solution of n-alkylamine for one day. The product was washed with hot water and dried. The n-alkylamine expanded CT was mixed with an ethanol solution of TEOS or AlAc for three days at room condition. The product was filtered and dried. The product was then mixed with water for one day. Finally, the product was washed and dried. Siliconamine was used to pillar CT by refluxing acidified CT with an aqueous solution of 3-aminopropyltrimethoxysilane for one day. The product was filtered, washed with acetone and dried. In addition, acidified CT was directly mixed with a solution of TEOS or AlAc. These samples were hydrolyzed, filtered, washed, and dried by the procedure used for pillaring n-alkylamine expanded CT. These samples (H-CT + TEOS) and $(\mathrm{H}-\mathrm{CT}+\mathrm{AlAc})$ were used for comparison with silica or alumina pillared CT (Si-CT or A!-CT).

$\mathrm{Si}-\mathrm{CT}$ and Al-CT after calcination at $723 \mathrm{~K}$ were used as supports for Mo and $\mathrm{Ni}$. Catalytic activities were evaluated by using hydrogenation of pyrene. Mo was loaded into SiCT by impregnation with an aqueous solution of ammonium molybdate(VI) tetrahydrate; and $\mathrm{Ni}$ from nickel(II) nitrate hexahydrate was then loaded by impregnation. The NiMo catalysts were calcined at $773 \mathrm{~K}$ and sulfided at $698 \mathrm{~K}$, or sulfided at $698 \mathrm{~K}$ only prior to catalytic evaluations. 


\subsection{Catalyst Characterization}

The concentrations of silicon and aluminum in pillared $\mathrm{CT}$ were determined by atomic absorption using a Varian AA-30 spectrophotometer. BET surface areas and pore size distributions were determined by nitrogen sorption using a Micromeritics Digisorb 2600 . Powder X-Ray diffraction patterns (XRD) were collected on an X-Ray diffractometer system Scintag Inc., model XDS2000 with copper radiation $(1=1.5405 \AA)$ at a scanning rate of $4 \%$ minute. The TEM micrographs of the titanates were made from a TEM microscopy, JEOL JEM-2010 $200 \mathrm{KV}$ TEM equipped with an ultrahigh resolution polepiece. The samples were prepared by dispersing the crystals in acetone and mounting them onto holey carbon filmed TEM grids. Conventional bright field imaging with electron diffraction techniques were used to character-ize the samples. The acidity of pillared CT was determined by temperature programmed desorption of ammonia using a heating rate of $12 \mathrm{~K} /$ minute.

The catalytic activities of sulfided $\mathrm{NiMo} / \mathrm{Si}-\mathrm{CT}$ or Al-CT were studied by pyrene hydrogenation at $573 \mathrm{~K}$. The reaction was performed in batch microreactors. The catalytic activity was evaluated by using the rate constant. The microreactor set-up and operation details were presented by Dosch and McLaughlin [11].

\section{RESULTS AND DISCUSSION}

\subsection{Characterization of Si-CT and Al-CT}

Type 2, 3, and 4 titanates (T2CT, T3CT, and T4CT) were used in this study. T2CT and T3CT have similar XRD patterns and basal spacings. However, there are significant differences in the preparations of T2CT and T3CT. Titanium(IV) isopropoxide was used as a titanium precursor for T2CT preparation, while hydrous titanium oxide was used for T3CT preparation. Aluminum nitrate nonahydrate was only used in the preparation of T2CT. The crystallization of T4CT was performed in a methanol solution, while an aqueous solution was used for T2CT and T3CT preparations. The basal spacing of T2CT and T3CT is $1.0 \mathrm{~nm}$, while the basal spacing of T4CT is $1.17 \mathrm{~nm}$.

In order to swell CT with n-alkylamine, it is necessary to replace $\mathrm{Na}^{+}$located between the layers by ion exchanging with an acidic solution. This phenomenon is very common for the swelling of layered titanate by n-alkylamine, even though n-alkylamine can be ionized in aqueous solution to form alkylammonium ion due to its high $\mathrm{pK}_{2}$. Izawa et.al. [12] reported that sodium trititanate and potassium tetratitanate could not be directly swelled by nalkylamine, unless they were acidified prior to the swelling. The basal spacing of T2CT could be increased to $3.29 \mathrm{~nm}$ using $\mathrm{n}$-dodecylamine (Udomsak and Anthony [10]). The basal spacings of $\mathrm{CT}$ after being swelled by n-hexylamine ware increased to $2.45,2.06$, and 2.26 $\mathrm{nm}$ for T2CT, T3CT, and T4CT, respectively. The basal spacings were increased to 2.51 and $2.65 \mathrm{~nm}$ for T2CT and T4CT respectively using n-octylamine. Nine weight\% of Mo was loaded into n-octylamine swelled T3CT by anion exchange at a pH of 3.5. However, only 3.8 weight \% of Mo could be loaded into T3CT prior to swelling. In this $\mathrm{pH}$ range the prevalent specie of ammonium molybdate in solution is $\mathrm{Mo}_{7} \mathrm{O}_{23}(\mathrm{OH})^{\mathrm{s}}$, a bulky anion. The increase of the ion exchange capacity after swelling indicates the layered structure of $\mathrm{CT}$ has been opened after being swelled by n-alkylamine.

Tetraethyl orthosilicate (TEOS) was loaded into n-octylamine swelled T2CT, n-hexylamine swelled T3CT and T4CT. Different TEOS concentrations in ethanol solutions were used to prepare silica pillared CT with Si:Ti molar ratios of 0.4 to 5.0. The sample identifications 
are $\operatorname{Si}(e t x)-T X C T-y$, where $X=$ type of titanate and $y=S i$ :Ti molar ratio in the solid. The XRD patterns of the Si(etx)-CT were similar to those of n-alkylamine swelled CT. A comparison between the TEM micrographs of acidified T2CT and Si(etx)-T2CT-0.4 clearly shows that the layers of Si(etx)-T2CT-0.4 were more separated than those of acidified T2CT, Figure 1. The basal spacing of Si(etx)-T2CT-0.4 determined by XRD was confirmed by the TEM micrograph.
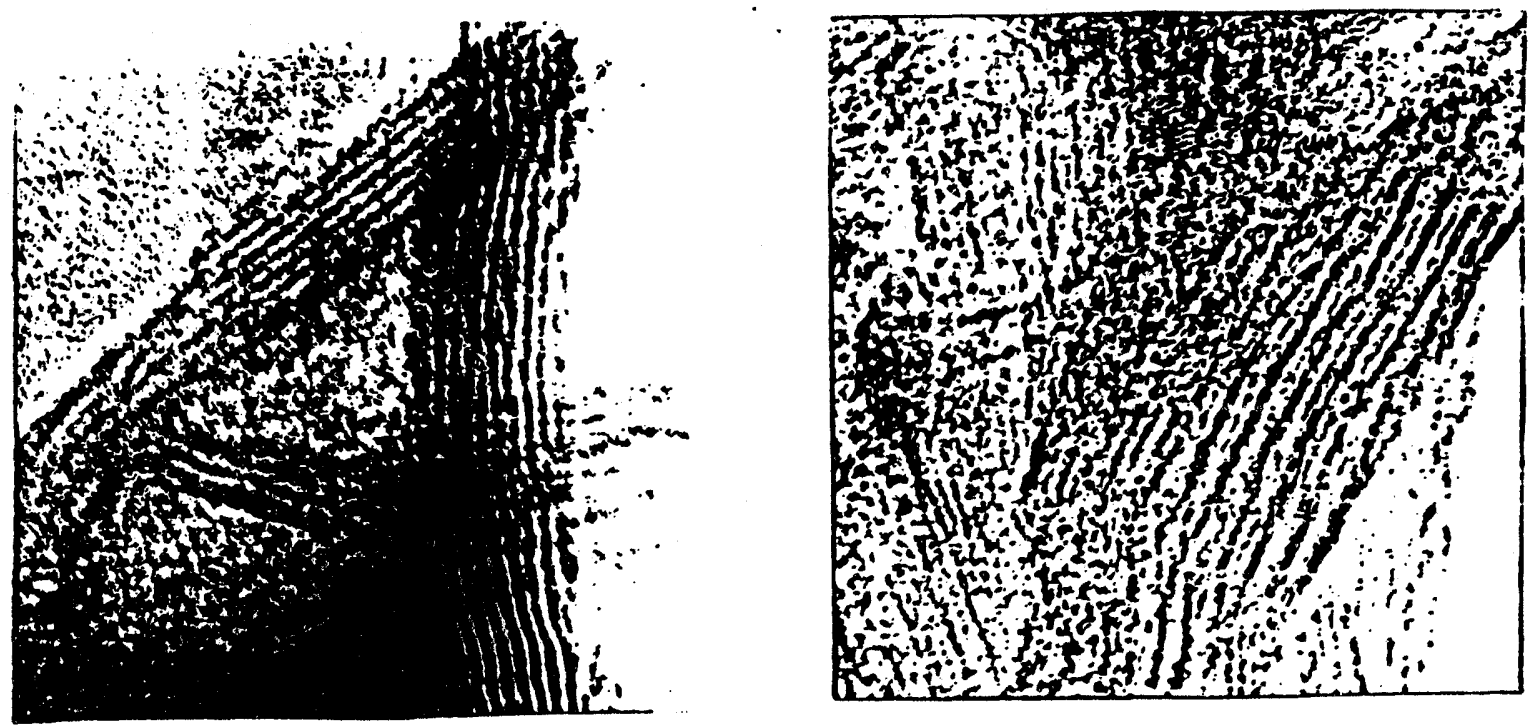

(a)

$$
1 \mathrm{~cm}=4.90 \mathrm{~nm}
$$

Figure 1. The TEM micrographs of (a) acidified T2CT and (b) Si(etx)-T2CT-0.4.

3-Aminopropyltrimethoxysilane was used to intercalate acidified T2CT. This sample $\mathrm{Si}(\mathrm{am})-\mathrm{T} 2 \mathrm{CT}-0.47$ has a Si:Ti molar ratio of 0.47 . The basal spacing was increased to 1.90 $\mathrm{nm}$ after being swelled by the siliconamine. The amount of intercalated siliconamine was equal to the ion exchange capacity of the solid.

Aluminum acetylacetonate (AlAc) was loaded into n-octylamine swelled T2CT and T3CT. The concentration of AlAc in the pillaring solution was varied in such a way that alumina pillared T2CT with Al:Ti molar ratios of 0.4 and 0.7 and alumina pillared T3CT with Al:Ti molar ratio of 0.5 were prepared. The XRD patterns of alumina pillared CT were similar to those of n-octylamine swelled CT. The basal spacings of Al-T2CT and Al-T3CT were 2.52 and $2.38 \mathrm{~nm}$ respectively.

Two heating procedures were used to study the thermal stability of Si-CT. First, the sample was degassed in a high vacuum $(P<0.025$ torr) at a temperature range of 373 to 723 $\mathrm{K}$. The temperature was raised to the desired temperature with a rate of $10 \mathrm{~K} / \mathrm{minute}$. Sample was loaded into an oven preset at $723 \mathrm{~K}$ for the second procedure. The heating period was four hours. The XRD patterns of Si(etx)-T2CT-0.4 after being heated by the procedures, illustrated in Figure 2, show that the basal spacing decreased from $2.51 \mathrm{~nm}$ to 1.07 nuth aftêr 


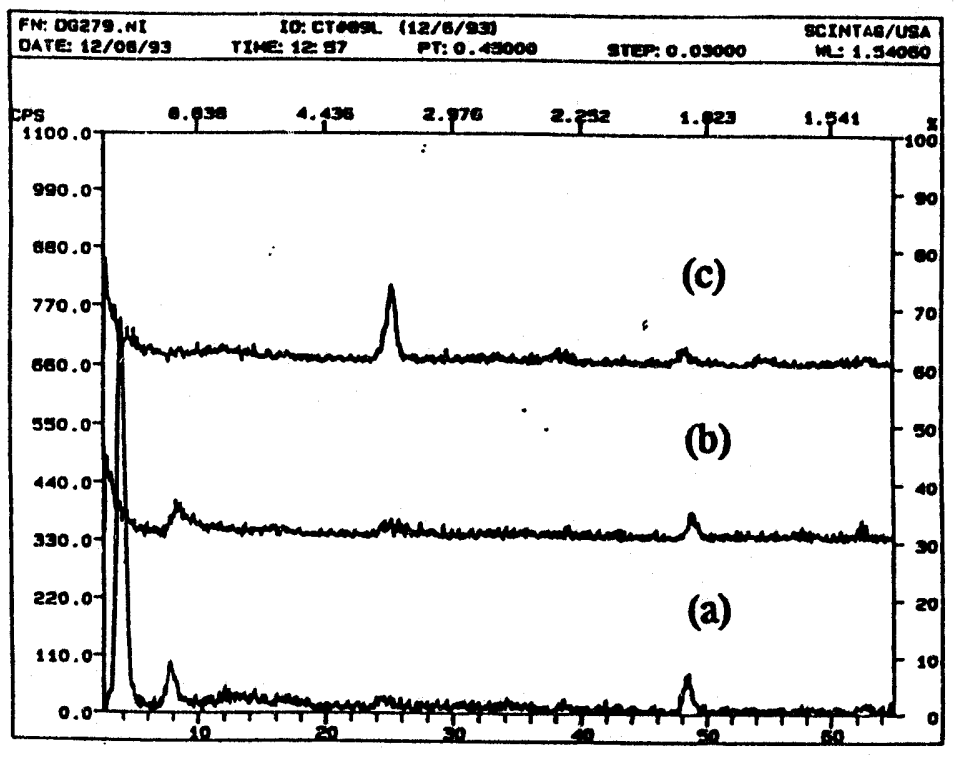

Figure 2. The XRD patterns of (a) as prepared Si(etx)-T2CT-0.4, (b) Si(etx)-T2CT-0.4 degassed at $723 \mathrm{~K}$, and (c) Si(etx)-T2CT-0.4 calcined in air at $723 \mathrm{~K}$.

degassing at $723 \mathrm{~K}$. However, after calcination at $723 \mathrm{~K}$ by the second procedure, the XRD pattern of Si(etx)-T2CT-0.4 indicates an amorphous material. The thermal stresses introduced by the abrupt change of temperature used in the second procedure may result in the collapse of the layers. The layers formed disoriented stacks of cards after being abruptly heated as illustrated by the TEM micrograph in Figure 3. The collapse of the layers was also observed for Si(etx)-T3CT heated by the second procedure. The XRD pattern of siliconamine intercalated T2CT after calcination by the second procedure also shows the collapse of the layers. The calcination procedure was also applied to Al-T2CT-0.4, Al-T2CT-0.7, and Al-T3CT-0.5. The XRD patterns of these alumina pillared $\mathrm{CT}$ indicates the collapse of the layered structures.

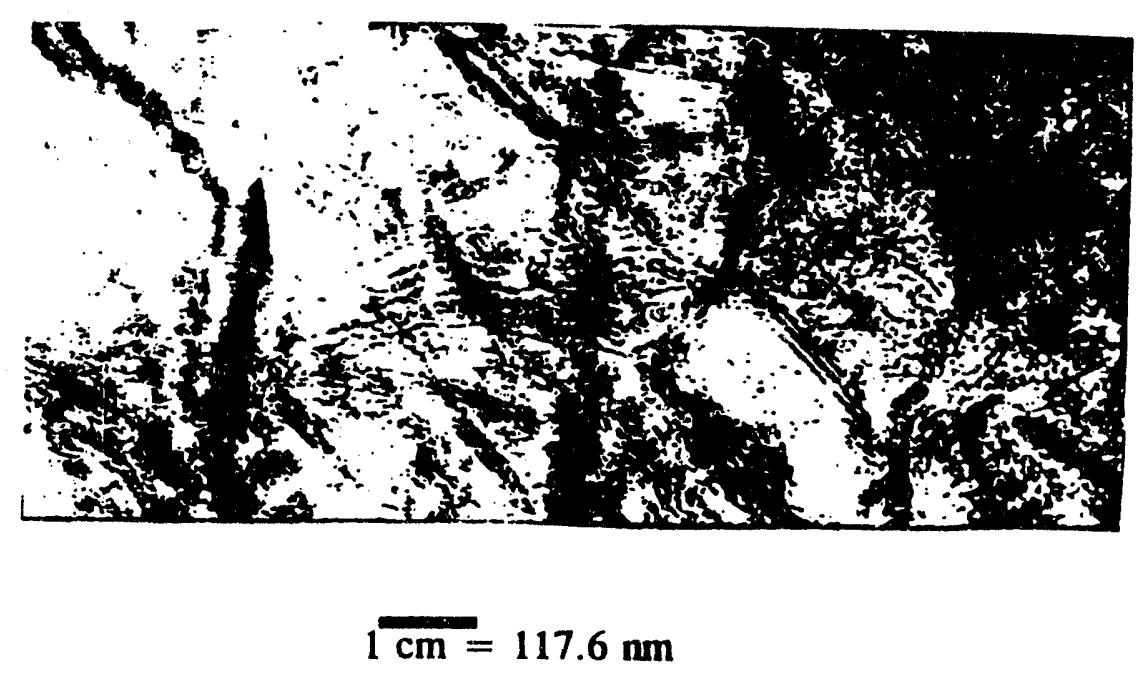

Figure 3. The TEM micrograph of calcined Si(etx)-T2CT-0.4. 
BET surface areas and pore structures of Al-CT and Si-CT were from isotherms of nitrogen sorption. The samples after calcination at high temperature were used instead of the samples degassed at high temperature since the basal spacing of the degassed sample (about $1.0 \mathrm{~nm}$ ) may be too small for pyrene, a reactant used in the activity experiments. As the silicon content increases, the surface area of Si-CT increases, illustrated in Table 1 . The same trend was also observed for Al-CT. Using TEOS as a pillaring agent yielded the most porous material among the samples with similar Si:Ti molar ratios. The surface areas of calcined Al$\mathrm{CT}$ and $\mathrm{Si}(\mathrm{am})-\mathrm{T} 2 \mathrm{CT}-0.47$ were in the same range. The surface areas of calcined Al-T2CT0.4 and $\mathrm{Si}(\mathrm{am})-\mathrm{T} 2 \mathrm{CT}-0.47$ were significantly higher than that of calcined T2CT (about 70 $\mathrm{m}^{2} / \mathrm{g}$ ). The surface areas of calcined (H-T2CT +TEOS) and (H-T2CT + AlAc), which were prepared without using n-alkylamine as a swelling agent, were 22 and $53 \mathrm{~m}^{2} / \mathrm{g}$, respectively. These surface areas were significantly lower than those of pillared CT.

Table 1. The surface areas, pore volumes, and silicon or aluminum contents of Si-CT and Al-CT after shock calcination at $723 \mathrm{~K}$ for four hours.

\begin{tabular}{lccc}
\hline \multicolumn{1}{c}{ Sample } & $\begin{array}{c}\text { Si or Al : Ti } \\
(\text { molar ratio })\end{array}$ & $\begin{array}{c}\text { Surface area } \\
\left(\mathrm{m}^{2} / \mathrm{g}\right)\end{array}$ & $\begin{array}{c}\text { Pore Volume } \\
(\mathrm{cc} / \mathrm{g})\end{array}$ \\
\hline T2CT & 0.00 & 70 & - \\
T3CT & 0.00 & $31^{\mathrm{a}}$ & - \\
T4CT & 0.00 & $19^{\mathrm{a}}$ & - \\
Si(am)-T2CT-0.47 & 0.47 & 168 & 0.55 \\
Si(etx)-T2CT-0.4 & 0.50 & 341 & 0.76 \\
Si(etx)-T2CT-5.0 & 5.00 & 974 & 1.76 \\
Si(etx)-T3CT-0.5 & 0.50 & 188 & 0.53 \\
Si(etx)-T3CT-5.0 & 5.00 & 308 & 0.38 \\
Si(etx)-T4CT-0.5 & 0.50 & 226 & 0.43 \\
Si(etx)-T4CT-5.0 & 5.00 & 243 & 0.32 \\
Al-T2CT-0.4 & 0.40 & 131 & 0.53 \\
Al-T2CT-0.7 & 0.70 & 193 & 1.12 \\
Al-T3CT-0.5 & 0.50 & 175 & - \\
\hline
\end{tabular}

${ }^{2}$ The samples were calcined at $773 \mathrm{~K}$.

As illustrated in Figure 4, the pore size distributions of the pillared CT are unimodal with the average pore diameters in the range of mesopores, defined in IUPAC classification as 2 to $50 \mathrm{~nm}$. The average pore diameters of Si(etx)-T2CT-0.4 and Si(am)-T2CT-0.47 were in the range of 5 to $7 \mathrm{~nm}$. However, the surface areas and pore volumes of Si(etx)-T2CT-0.4 were significantly greater than those of $\mathrm{Si}(\mathrm{am})-\mathrm{T} 2 \mathrm{CT}-0.47$. The pore volume and pore size distribution of Al-T2CT-0.7 indicates that it is much more porous than Al-T2CT-0.4, even though the difference between the surface areas of the two samples was small. 


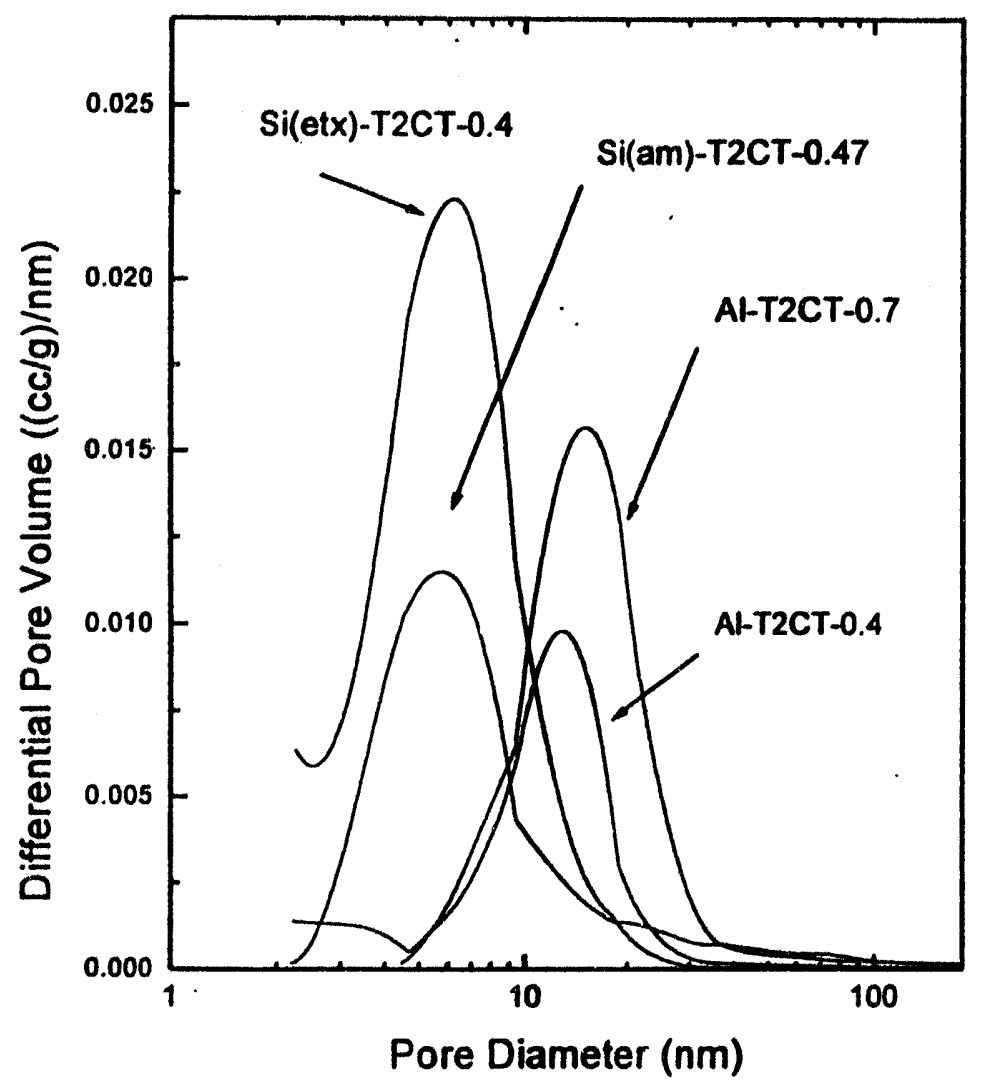

Figure 4. The pore size distributions of silica and alumina pillared CT after calcination at $723 \mathrm{~K}$ for four hours.

The acidities of Si(etx)-T2CT-0.4, Si(etx)-T2CT-5.0, and Si(am)-T2CT-0.47 were determined by temperature programmed desorption of ammonia and compared with the profile of commercially available $\gamma$ alumina (Strem Chemical, Inc.). The acid densities of these samples were $4.4^{*} 10^{13}, 2.9^{*} 10^{13}, 3.4^{*} 10^{13}$, and $1.2 * 10^{12}$ molecules of $\mathrm{NH}_{3}$ desorbed $/ \mathrm{cm}^{2}$ for $\gamma$ alumina, $\mathrm{Si}(\mathrm{am})-\mathrm{T} 2 \mathrm{CT}-0.47, \mathrm{Si}(\mathrm{etx})-\mathrm{T} 2 \mathrm{CT}-0.4$, and $\mathrm{Si}(\mathrm{etx})-\mathrm{T} 2 \mathrm{CT}-5.0$, respectively. The acid site distribution of $\mathrm{Si}(\mathrm{etx})$-T2CT- -0.4 is bimodal with peaks at $523 \mathrm{~K}$ and $623 \mathrm{~K}$, while the site distributions of $\mathrm{Si}(\mathrm{am})$-T2CT- -0.47 and $\mathrm{Si}(\mathrm{etx})$-T2CT-0.4 are unimodal with a peak at $503 \mathrm{~K}$. In general, as the silicon content increases, the acid density decreases. Using siliconamine as pillaring agent yielded a sample with less acid density than that of a sample prepared by TEOS, for the samples with similar Si:Ti molar ratios. However, the site distribution of a sample prepared by siliconamine is much more uniform than that of a sample prepared with TEOS. Si-T2CT were less acidic than $\gamma$ alumina. 


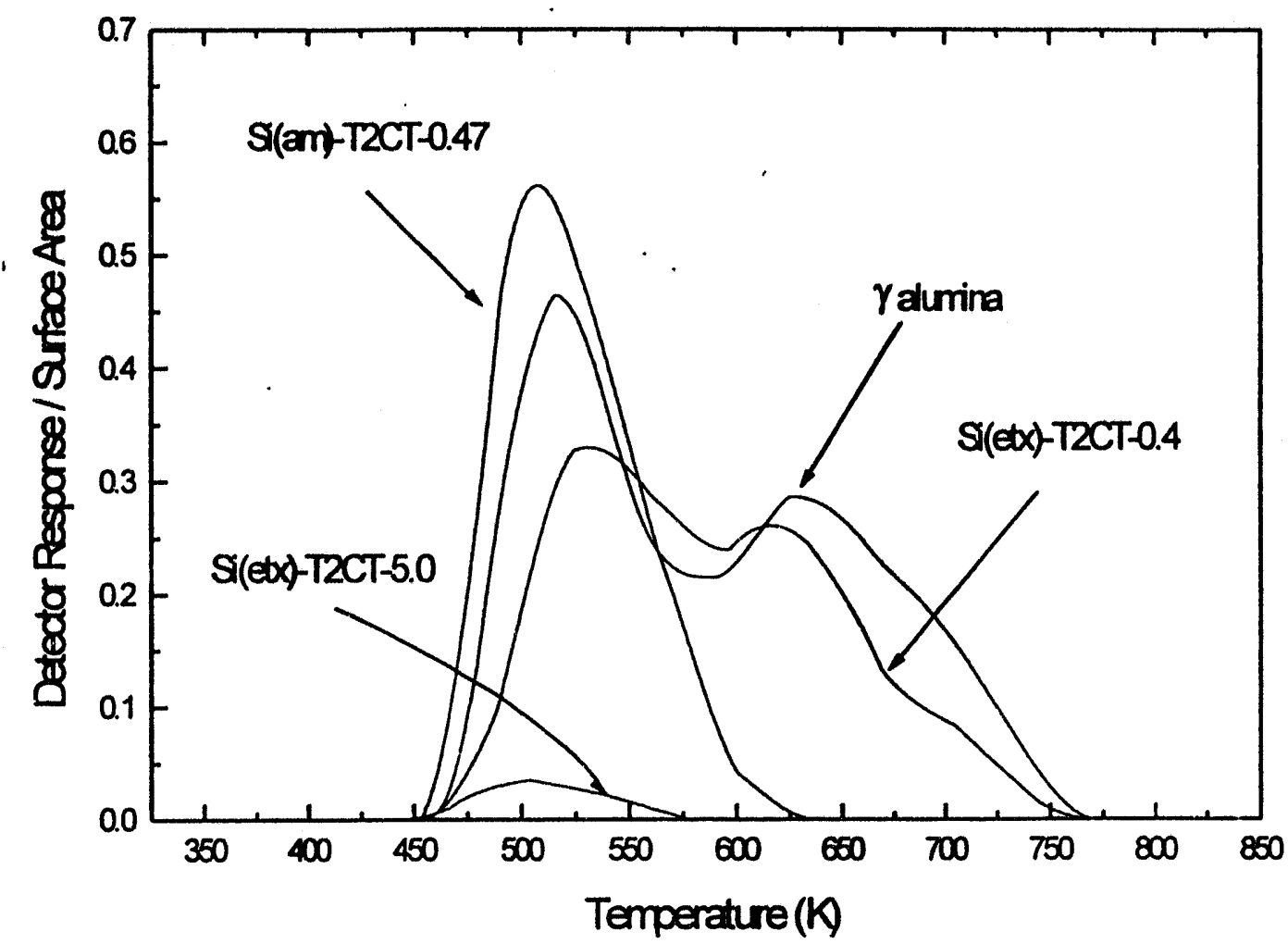

Figure 5. The comparison of the TPD profiles of ammonia on Si-T2CT and $\gamma$ alumina.

\subsection{Catalytic activities}

The rate coristant for pyrene hydrogenation was used to evaluate the activities of sulfided NiMo catalyst. The activities for this model reaction have been shown to correlate with the ultinate activity for coal liquefaction (Stephens et. al. [13-15]). A comparison of pyrene hydrogenation activities of sulfided NiMo/Si-CT and Al-CT with Shell324 and Amocat1C is presented in Table 2. The data in Table 2 illustrate the effect on rate constant of the Si or Al:Ti molar ratios in the pillared CT. For the samples prepared with TEOS, (Si(etx)-T2CT, Si(etx)-T3CT, and Si(etx)-T4CT) and with similar Mo and Ni loadings, the activities were inversely proportional to the Si:Ti molar ratios in the supports. When comparing Al-T2CT and Al-T3CT, the trend was opposite. As the Al:Ti molar ratios in the supports increase, the catalysts become more active. NiMo/Si(etx)-T2CT was the most active catalyst, for the supports prepared by TEOS with the Si:Ti molar ratios in the range of 0.4 to 0.5 , while Si(etx)-T4CT was the least active. The support prepared by TEOS, Si(etx)-T2CT-0.4, is a more active catalyst than the sample prepared by siliconamine $\mathrm{Si}(\mathrm{am})-\mathrm{T} 2 \mathrm{C} \mathrm{r}-0.47$, even though they were prepared from the same type of titanate and have similar Si:Ti molar ratios. In general, calcination and sulfiding is a better way to activate the catalyst than sulfiding only. However, this phenomenon was opposite for $\mathrm{NiMo/Si(etx)-T2CT-0.4} \mathrm{which} \mathrm{was} \mathrm{the} \mathrm{most}$ active NiMo/Si-CT catilyst. The activity of NiMo/Si(etx)-T2CT-0.4 was more active than commercial catalysts, while using a lesser amount of Mo. The activity of NiMo/Al-T2CT-0.7 
was comparable to commercial catalyst. However, the Mo loading was only half of those of commercial catalysts. The catalytic activities of $\mathrm{NiMo} / \mathrm{Si}-\mathrm{T} 2 \mathrm{CT}$ correlate with the acid densities of the supports. For example, Si(etx)-T2CT-0.4 which was the most active catalyst has the highest acid density, while Si(etix)-T2CT-5.0 which was the least active has the lowest acid density.

Table 2. The comparison of catalytic activities among NiMo/Si-CT and Al-CT, NiMo/hydrous metal oxide, and commercial catalysts for pyrene hydrogenation.

\begin{tabular}{|c|c|c|c|c|c|}
\hline Support & $\begin{array}{l}\text { Si or } \mathrm{Al}: \mathrm{Ti} \\
\text { molar ratio }\end{array}$ & $\begin{array}{c}\text { Mo } \\
\text { (wt \%) }\end{array}$ & $\begin{array}{c}\mathrm{Ni} \\
(\mathrm{wt} \%)\end{array}$ & $\begin{array}{c}\mathbf{k}_{\text {pyr }}^{\text {coul }} \\
(\mathrm{g} \text { cat.sec })^{-1}\end{array}$ & $\begin{array}{c}\mathbf{k}_{\text {pyr }}^{{ }^{\text {Mo }}} \\
(\mathbf{g ~ M o . s e c})^{-1} \\
\end{array}$ \\
\hline Shell324 & - & 13.2 & 2.7 & $0.158^{\mathrm{cas}}$ & $1.20^{\mathrm{cks}}$ \\
\hline Amocat1C & - & 10.7 & 2.4 & $0.155^{\mathrm{ces}}$ & $1.45^{\mathrm{cas}}$ \\
\hline $\mathrm{Na}_{0.5} \mathrm{TiSi}_{0.25}{ }^{\mathrm{a}}$ & 0.25 & 9.6 & 3.2 & $0.207^{\text {cas }}$ & $2.16^{\mathrm{cas}}$ \\
\hline $\mathrm{Si}(\mathrm{am})-\mathrm{T} 2 \mathrm{CT}-0.47$ & 0.47 & 10.4 & 3.5 & $\begin{array}{l}0.124^{\mathrm{s}} \\
0.146^{\mathrm{cas}}\end{array}$ & $\begin{array}{l}1.19^{\mathrm{s}} \\
1.40^{\mathrm{ces}}\end{array}$ \\
\hline $\mathrm{Si}(\mathrm{etx})-\mathrm{T} 2 \mathrm{CT}-0.4$ & 0.40 & 8.7 & 3.4 & $\begin{array}{l}0.206^{\mathrm{S}} \\
0.180^{\text {cas }}\end{array}$ & $\begin{array}{l}2.37^{\mathrm{s}} \\
2.07^{\mathrm{ces}}\end{array}$ \\
\hline $\mathrm{Si}(\mathrm{etx})-\mathrm{T} 2 \mathrm{CT}-5.0$ & 5.00 & 7.5 & 2.9 & $\begin{array}{l}0.110^{\mathrm{s}} \\
0.115^{\mathrm{ces}}\end{array}$ & $\begin{array}{l}1.47^{\mathrm{s}} \\
1.54^{\mathrm{ces}}\end{array}$ \\
\hline $\mathrm{Si}(\mathrm{et} x)-\mathrm{T} 3 \mathrm{CT}-0.5$ & 0.50 & 9.6 & 3.2 & $\begin{array}{l}0.101^{\mathrm{s}} \\
0.131^{\operatorname{cas}}\end{array}$ & $\begin{array}{l}1.05^{\mathrm{s}} \\
1.45^{\mathrm{ces}}\end{array}$ \\
\hline Si(etx)-T3CT-5.0 & 5.00 & 9.6 & 3.2 & $\begin{array}{l}0.080^{\mathrm{s}} \\
0.093^{\mathrm{cas}}\end{array}$ & $\begin{array}{l}0.83^{\mathrm{s}} \\
0.97^{\text {cas }}\end{array}$ \\
\hline $\mathrm{Si}(\mathrm{etx})-\mathrm{T} 4 \mathrm{CT}-0.5$ & 0.50 & 9.6 & 3.2 & $\begin{array}{l}0.093^{\mathrm{s}} \\
0.122^{\mathrm{cas}}\end{array}$ & $\begin{array}{l}0.97^{\mathrm{s}} \\
1.27^{\mathrm{cos}}\end{array}$ \\
\hline $\mathrm{Si}(\mathrm{etx})-\mathrm{T} 4 \mathrm{CT}-5.0$ & 5.00 & 9.6 & 3.2 & $\begin{array}{l}0.092^{\mathrm{s}} \\
0.106^{\mathrm{cks}}\end{array}$ & $\begin{array}{l}0.96^{\mathrm{s}} \\
1.10^{\text {cas }}\end{array}$ \\
\hline $\mathrm{Al}-\mathrm{T} 2 \mathrm{CT}-0.4$ & 0.40 & 7.3 & 2.0 & $\begin{array}{l}0.094^{\mathrm{s}} \\
0.027^{\mathrm{cas}}\end{array}$ & $\begin{array}{l}1.28^{\mathrm{s}} \\
0.37^{\mathrm{ces}}\end{array}$ \\
\hline Al-T2CT-0.7 & 0.70 & 6.3 & 2.2 & $\begin{array}{l}0.118^{s} \\
0.126^{\text {cas }}\end{array}$ & $\begin{array}{l}1.87^{\mathrm{s}} \\
2.00^{\mathrm{css}}\end{array}$ \\
\hline Al-T3CT-0.5 & 0.50 & 8.6 & 2.8 & $\begin{array}{l}0.064^{\mathrm{s}} \\
0.128^{\mathrm{ces}}\end{array}$ & $\begin{array}{l}0.74^{\mathrm{s}} \\
1.49^{\text {ces }}\end{array}$ \\
\hline $\begin{array}{ll}\mathrm{da}_{0.5} \mathrm{TiSi}_{0.25} & =\mathrm{an} \\
\mathrm{S} & =\mathrm{Th} \\
\mathrm{C} \& \mathrm{~S} & =\mathrm{Th}\end{array}$ & $\begin{array}{l}\text { Iphous } \\
\text { alyst w } \\
\text { alyst w }\end{array}$ & $\begin{array}{l}\text { I pre } \\
\text { led o } \\
\text { ned a }\end{array}$ & & & \\
\hline
\end{tabular}




\section{CONCLUSIONS}

High surface area and mesoporous materials can be prepared from calcined silica or alumina pillared crystalline titanates (Si-CT and Al-CT). Tetraethyl orthosilicate and aluminum acetylacetonate can be used to pillar CT by first swelling the CT with n-alkylamine prior to pillaring, while 3-aminopropyltrimethoxysilane could directly pillar CT without preswelling it by n-alkylamine. The pillared CT, when used as supports for Mo and Ni show considerable activities for pyrene hydrogenation. The activity and the acidity of the support are very well correlated to the $\mathrm{Si}$ or $\mathrm{Al}$ :Ti molar ratios in the solids. The most active catalyst $\mathrm{NiMo} / \mathrm{Si}(\mathrm{etx})$-T2CT was more active than commercial catalysts, while using less Mo. Moreover, the activity of NiMo/Al-T2CT- 0.7 was comparable to commercial catalysts, while the amount of Mo was only half of those of commercial catalysts. Therefore, Si-CT and AlCT have a high potential for use as supports for coal liquefaction.

\section{REFERENCES}

1. R.G. Anthony and R.G. Dosch, in G. Poncelet, P.A. Jacobs, P. Grange and B. Delmon (eds.), Preparation of Catalysis V., Elsvier Science Publisher B.V., Amsterdam, 1991, p. 637.

2. R.G. Anthony and R.G. Dosch, US Patent 5177045 (1993).

3. R.G. Anthony, E. Gonzalez, C.V. Philip and R.G. Dosch, Catal.Today., 14 (1992) 253.

4. A. Clearfield and M.E. Kuchenmeister, in T. Bein (ed.), Supramolecular Architecture: Synthetic Control in Thin Films and Solids, ACS Symposium Series 499, American Chemical Society, Washington D.C., 1992, p. 128.

5. A. Clearfield, M.E. Kuchenmeister, K. Wade, R. Cahill and P. Sylvester, in M.L. Occelli and H.E. Robinson (eds.), Expanded Clays and Other Microporous Solid, Van Nostrand Reinhold, New York, 1992, p. 245.

6. S. Cheng and T.C. Wang, Inorg. Chem., 27 (1989) 3237.

7. M.E. Landis, P.Chu, I.D. Johnson, G.W. Kirker, M.K. Rubis and B. Cynwyd, US Patent 4859648 (1989).

8. M.E. Landis, B.A. Aufdenbrink, P. Chu, I.D. Johnson, G.W. Kirker and M.K. Rubin, J. Am. Chem. Soc., 113 (1991) 3189.

9. L. Li, X. Liu, Y. Ge, L. Li and J. Klinowski, J. Phys. Chem., 95 (1991) 5910.

10. S. Udomsak and R.G. Anthony, Catal. Today., (submitted).

11. R.G. Dosch and L.I. McLaughlin, SAND92-0388, Sandia National Laboratories, 1992.

12. H. Izawa, S. Kikkawa and M. Koizumi, Polyhedron, 2 (8) (1983) 741.

13. H.P. Stephens and R.N. Chapman, Preprints, Fuel. Div., ACS, 28 (5) (1983) 161.

14. H.P. Stephens and F.V. Stohl, Preprints, Fuel. Div., ACS, 29 (6) (1984) 79.

15. H.P. Stephens and R.J. Kottenstette, Preprints, Fuel. Div., ACS, 30 (2) (1985) 345. 

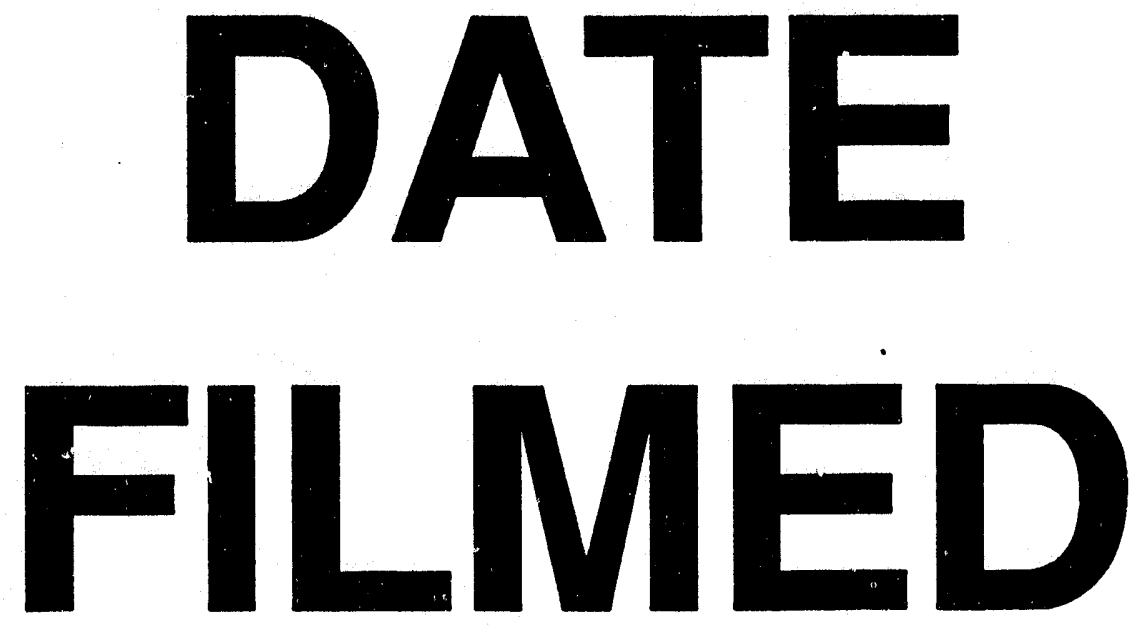

$7 / 8 / 94$
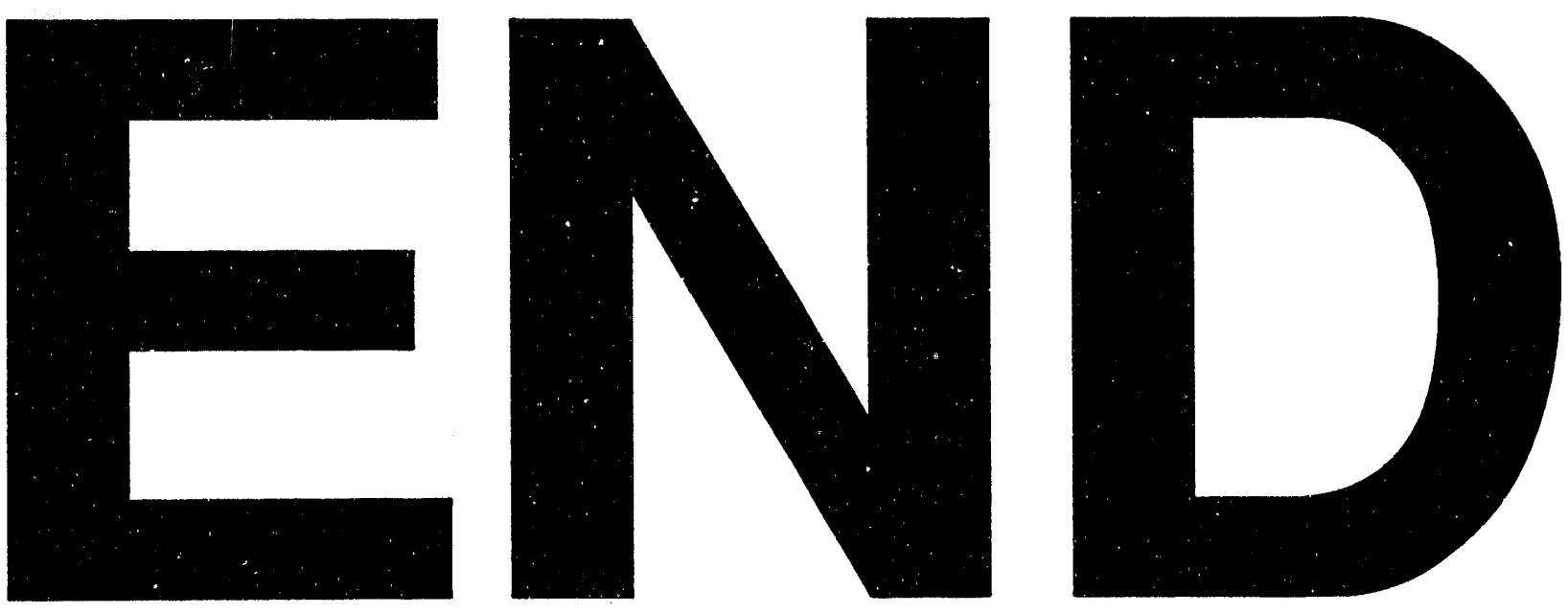

4 


$$
+
$$

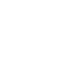

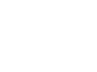

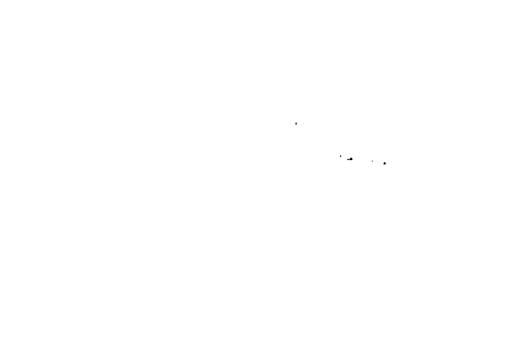

